\title{
Rationalizing predictably irrational choices: the social capital synthesis
}

\author{
Lindon J. Robison ${ }^{1}$ (D) . Jeffrey R. Oliver ${ }^{2}$
}

Received: 25 February 2019 / Accepted: 19 September 2019

(c) The Author(s) 2019

\begin{abstract}
This paper presents a synthesis of the main characteristics of neoclassical, behavioral, and socioeconomic models. The main characteristics of this synthesis is that it includes social capital-produced relational goods whose value and meaning depend on their connections to people. We contrast relational goods with commodities. Then, we examine whether the synthesis can resolve some of the sometimes conflicting explanations and predictions of economic exchange models. Finally, we apply the synthesis to rural development and find it provides useful explanations and recommendations.
\end{abstract}

JEL Classification A11 A A12 - A13 · A14

\section{Introduction}

This paper presents a synthesis of key characteristics of the neoclassical, behavioral, and socioeconomic models capable of resolving some frequent and important conflicts between neoclassical economic theory and observed behavior. Such conflicts have been described as economic agents "misbehaving" (Thaler 2016) or making "predictably irrational" choices (Ariely 2008). In addition, Thaler and Sunstein described "Nudges" that change economic behavior without offering traditional economic incentives (Thaler and Sunstein 2008).

We organize our description and discussion of the synthesis capable of rationalizing important economic anomalies into the following sections. The first section describes the proposed synthesis. The second section describes the difference

Lindon J. Robison

robison@msu.edu

Jeffrey R. Oliver

oliverj@byui.edu

1 Agricultural and Resource Economics (AFRE), Michigan State University, East Lansing, USA

2 Department of Sociology and Social Work, Brigham Young University-Idaho, Rexburg, USA 
between commodities, the focus of neoclassical economics, and relational goods, the focus of the proposed synthesis. The third section illustrates how the proposed synthesis resolves several well-known economic anomalies. Finally, we address how the synthesis can inform the study of important applied topics, including the study of rural development.

\section{A proposed social capital synthesis}

To resolve some frequently observed economic anomalies, we need a more general model than the traditional neoclassical economic one. Thaler called for such a model that describes individuals who do the best they can but who also have the "human strengths of kindness and cooperation, together with the limited human abilities to store and process information" (Thaler 1992, p. 5). The social capital synthesis presented next, is our response to Thaler's recommendation. To capture the essence of relationships in the synthesis, we include social capital and refer to result as the social capital synthesis.

Model assumptions Before presenting the proposed social capital synthesis of key elements of the neoclassical, behavioral, and socioeconomic models, we make clear their underlying assumptions. The neoclassical economic model assumes agents are perfectly informed, selfish, and rationally pursuing exchanges that maximize their well-being defined by commodity accumulations. We require that the social capital synthesis be capable of describing and predicting behavior consistent with the neoclassical synthesis when such a model applies.

Behavioral economist Richard Thaler, recent winner of the Nobel Prize in economics, provided one description of behavioral economics assumptions when he claimed that people are "dumber and nicer" and more human compared to "econs" described in graduate economics texts (Thaler 2016). Therefore, we include as a synthesis requirement that agents are more "kind and cooperative" than described in neoclassical economics when such a model applies.

Socioeconomists assume that relationships matter (Etzioni 2010). One socioeconomic model views relationships of sympathy, empathy, trust, and regard as a form of capital, social capital, that can produce intangible socio-emotional goods (SEGs) that can embed themselves in things, creating tangible attachment value goods (AVGs) (Robison and Ritchie 2010). We include social capital as an essential assumption in the synthesis.

Social capital synthesis assumptions We propose a social capital synthesis of the neoclassical, behavioral, and socioeconomic models that includes social capital-produced SEGs and AVGs in utility maximizing exchanges (Robison and Flora 2003). We claim that including SEGs and AVGs in the traditional neoclassical model alters the terms and level of exchange compared to commodity exchanges and can explain 
much of predictably irrational behavior including agents who are more caring and cooperative.

The synthesis argues that the assumptions of neoclassical, behavioral, and socioeconomic all apply - but under different conditions, not all of the time, nor all at once. We now consider some conditions under which the alternative assumptions underlying neoclassical, behavioral, and socioeconomics may apply.

When strangers exchange commodities, the synthesis predicts that economic agents will behave like "econs." In these circumstances, economic agents will pursue their selfish interests and seek to maximize their well-being measured by their commodity accumulations. When social capital-rich exchange partners engage in economic exchanges, the synthesis predicts they will include SEGs and AVGs that alter the terms and level of exchange compared to commodity exchanges between "econs" and social capital-rich agents will appear to be both "dumber" and "nicer" than "econs."

We defend the proposed synthesis by using it to resolve examples of misbehaving and predictably rational exchanges. However, we acknowledge that to establish it as a legitimate paradigm will require more research and tests. We call for such efforts.

\section{Commodities and relational goods}

The social capital synthesis describes economic agents who exchange commodities and relational goods. We describe and compare these two classes of goods in what follows.

What are commodities? Commodities consist mostly of physical goods and services whose value is associated with their ability to satisfy mostly physical needs.

What are relational goods? A relational good is one whose value and meaning depends in part on its connections to people (Oliver and Robison 2017). ${ }^{1}$

What kind of capital is required to produce commodities and relational goods? In mainstream economics, the production of commodities employs manufactured capital (tools and implements), natural resource capital, human capital, and financial capital. All of these forms of capital contribute to the creation of a good or service valued for its mostly observable physical properties. In contrast, we produce relational goods in sympathetic, empathetic, trusting, and high regard relationships referred to here and by others as social capital.

How do we produce commodities and relational goods? We produce commodities mostly when we change their physical natures through production processes that

\footnotetext{
1 For additional relational good references, see Bruni and Stanca (2008), Gui and Sugden (2005), Gui and Stanca (2010), Becchetti (2008), Luigino and Stanca (2008) and Uhlaner (1989).
} 
employ other tangible goods and time. We may change the physical nature of commodities by changing the good's taste, color, availability, location, form, content, age, and ability to combine with other goods.

Social capital-rich exchange partners who empathize, sympathize, trust, and admire each other produce intangible SEGs capable of satisfying socio-emotional needs. When SEGs embed in things, we refer to the embedded things as AVGs. Though not always called by that name, AVGs are abundant in social life. Examples include wedding rings, meaningful songs, family photographs, hometowns, artifacts in museums, religious symbols, mementos of emotionally charged experiences, and prized family heirlooms.

What needs do commodities and relational goods satisfy? Commodities satisfy mostly physical needs and wants. Relational goods satisfy mostly socio-emotional needs. While there is no universally accepted list of socio-emotional needs relational goods are expected to satisfy, generally accepted needs include the need for internal validation or self-actualization, the need for external validation, the need for connectedness (belonging, love and friendship), and the need for knowing (Maslow 1943).

How do exchange conditions for commodity and relational goods differ? We exchange commodities in mostly impersonal settings. Furthermore, we do not generally connect with those that produce, market, or otherwise make commodities available for exchange. As a result, commodities do not acquire attachment value. One can think of impersonal exchanges with a vending machine, on-line purchases, self-serve gasoline stations, and ATM machines as settings conducive to commodity exchanges.

We exchange relational goods in personalized settings where either the buyer and/or the seller provide each other social capital or have social capital connections with those who made the good available for exchange. Relational good exchanges may include giving gifts to friends and family; buying or selling goods on preferential terms of trade; supporting special causes to which we have connections; obeying rules embedded with SEGs even though we may experience commodity costs in the process; and emphasizing social connections to complete a commodity exchange.

How are terms and levels of exchange for commodities and relational goods determined? The terms and levels at which commodities are exchanged are determined by the aggregate of market participants and apply generally to similar commodities. The terms and levels at which relational goods are exchanged depend on the social capital between those who consume, produce, market, and preserve the good and the value of the commodity included in the exchange.

How does the substitutability of commodities and relational goods differ? Commodities are standardized goods of uniform quality. These qualities make them nearly perfect substitutes for each other when they satisfy the same needs. Gasoline 
purchased at one gasoline station is nearly a perfect substitute for gasoline purchased at a different gasoline station.

Each relationship has a different capacity to produce relational goods, and therefore, relational goods are relatively poor substitutes for each other unless they depend on similar forms of social capital. To illustrate, gasoline sold at a gas station owned by a friend or relatives is not a perfect substitute for gasoline sold at a station owned by a stranger because relational goods are likely included in the purchase.

How do we value commodities and relational goods? We infer the value of commodities from their (mostly) observable physical properties and the importance of the physical needs they satisfy. The value of relational goods depends in part on unobservable SEGs produced in social capital-rich relationships. Still, we can often observe the conditions that produced the unobservable SEGs. For example, a baseball purchased at a sporting goods store is valued differently than the physically identical baseball hit for a home run by a famous player in an important playoff game. An item of clothing identified with a person with a large fan base (read social capital provided by a large network of fans) is valued more than the same item not associated with a famous person.

How does the durability of relational goods and commodities differ? Commodities are mostly nondurable goods unlikely embedded with SEGs because of their short economic life. The exception might be when a nondurable good represents a durable brand or it is consumed repeatedly. For example, a special dessert may be a nondurable. However, when it is served repeatedly at special events where persons in a social capital-rich network gather, the dessert may gain attachment value.

Differences in the certification of commodities and relational goods Commodities are most likely to have their quantity and quality certified by arm's length agencies established for that purpose. Relational goods are most likely to have their quantity and quality assured by the social capital inherent in relationships.

\section{Commodity and relational good exchanges}

This paper accepts the general premise of social exchange theory that social life is a series of human exchanges. Homans (1958) defined social exchange theory as a social activity in which at least two or more persons exchange tangible and intangible objects. Blau (1964) and Emerson (1976) both noted that social exchanges produce both social and economic outcomes. What distinguishes economic and social exchanges are the nature of the goods exchanged and the relationship between persons directly or indirectly included in the exchange.

Increasingly, social scientists use social capital to describe the nature of relationships between persons engaged in social exchanges. The origin of the social 
capital concept can be attributed to Adam Smith who described our natural tendency to sympathize (empathize) with others. "How selfish soever man may be supposed, there are evidently some principles in his nature, which interest him in the fortune of others, and render their happiness necessary to him, though he derives nothing from it, except the pleasure of seeing it." (Smith 1759, 1776)

The difficulty with the social capital concept is that so many claim to have given it birth and ascribe to it characteristics of their own genealogy. Such traits are often peculiar to the study of sociology, political science, anthropology, economics, management, or psychology. Second, instead of defining social capital (i.e., concept A equals concept B), many proposed social capital definitions focus on what it can be used to achieve, where it lives, how it is organized, and how it can be produced. Then, there is the problem of social capital definitions defining a concept that is neither social nor that satisfies the requirements of being capital.

Portes and Sensenbrenner defined social capital as "the expectations for action within a collectivity that affect the economic goals and goal-seeking behavior of its members" (Portes and Sensenbrenner 1993). This definition appears to focus on what social capital can achieve, namely influencing the economic goals and goalseeking behavior of its members.

Coleman described social capital as a variety of different entities having some aspect of social structure and ability to facilitate certain actions within the structure (Coleman 1990). Coleman's definition seems to combine what social capital is, social structure, with what it can be used to achieve-certain actions within the structure.

Burt defined social capital as friends, colleagues, and more general contacts through whom you receive opportunities to use other forms of capital (Burt 1992: 9). This social capital definition seems to focus on where social capital lives, with friends, colleagues, and other contacts.

Fukuyama (2001) defines social capital as generally understood rules than enable people to cooperate including norms of reciprocity or religious doctrine like Christianity. This social capital definition connects it to rules and institutions that organize its use.

While the many proposed social capital definitions help us understand the nature of social capital, there is no consensus social capital definition. Nevertheless, among the most prominent social capital definitions is a focus on social relationships. For example, Putnam defined social capital as "connections among individuals-social networks and the norms of reciprocity and trustworthiness that arise from them." (Putnam 2001).

Because there are so many social capital definitions available, we must choose one that is most consistent with the goal of the social capital synthesis-to explain behavior that is sometimes consistent with neoclassical economics and sometimes consistent with predictions and observations of behavioral and socioeconomics. In our opinion, Adam Smith's description of social relationships as gradations of sympathy (empathy) that are capable of producing relational goods provides the foundation for a social capital definition suitable for the purposes of the social capital synthesis. Smith wrote, "Every man feels his own pleasures and his own pains more sensibly than those of other people. After himself, the members of his own family, 
those who usually live in the same house with him, his parents, his children, his brothers and sisters, are naturally the objects of his warmest affection" (Smith 1759).

In the tradition of Adam Smith with his focus on sympathy (empathy), Robison, Schmid, and Siles (RSS) defined social capital as “a person's or group's sympathy (empathy) toward another person or group that may produce a potential benefit, advantage, and preferential treatment for another person or group of persons beyond that expected in an arm's length exchange relationship" (Robison et al. 2002). Such a definition is of the form concept A (social capital) is equal to concept $B$ (sympathy, empathy, regard, trust). Moreover, social capital (sympathy/empathy) satisfies an important capital requirement by producing relational goods and creating other forms of capital including other social capital relationships. For these reasons, the social capital synthesis adopts the RSS social capital definition.

A synthesis exchange summary Table 1 describes the essence of the proposed social capital synthesis. The four quadrants in Table 1 -northwest (NW), northeast (NE), southwest (SW), and southeast (SE)—describe four types of exchanges included in the synthesis. We describe the kinds of objects exchanged under columns labeled commodity exchanges and relational good exchanges. We describe alternative relationships that may exist between persons exchanging commodities and relational goods on rows labeled social capital-rich relationships and arm's length relationships such as would exist between strangers (Mastroeni 2017).

Treating exchanges in quadrants NW, NE, and SE as though they occurred in quadrant SW would lead us to infer that agents are behaving predictably irrational or misbehaving. We emphasize that by recognizing the distinctive nature of exchanges in quadrants NW, NE, and SE, we can explain observed behavior that differs from exchanges predicted in the SW quadrant.

How relationships influence the terms and level of trade and the nature of goods exchanged Figure 1 captures the essence of exchanges that include both commodities and relational goods between persons in social capital-rich networks and strangers. The vertical axis measures the commodity values included in the exchange, while the horizontal axis measures relational goods included in the exchange. Isoutility lines included in Fig. 1 for both buyers and sellers represent combinations of commodities and relational goods valued equally.

If no relational goods are included in the exchange, there are no terms of trade for commodities acceptable to both the buyer and seller because the seller's minimum sell price is greater than the buyer's maximum bid price. However, when relational goods greater than $\mathrm{OE}$ and less than $\mathrm{OG}$ are included in the exchange, then there are commodity prices represented by the vertical line between the two isoutility lines that would be acceptable to both buyers and sellers. Furthermore, if a sufficient quantity of relational goods are included in the exchange, greater than OG, then the seller is willing to offer the good to the buyer as a gift. If one attempted to describe the terms and level of exchange by only reporting commodities exchanged, 


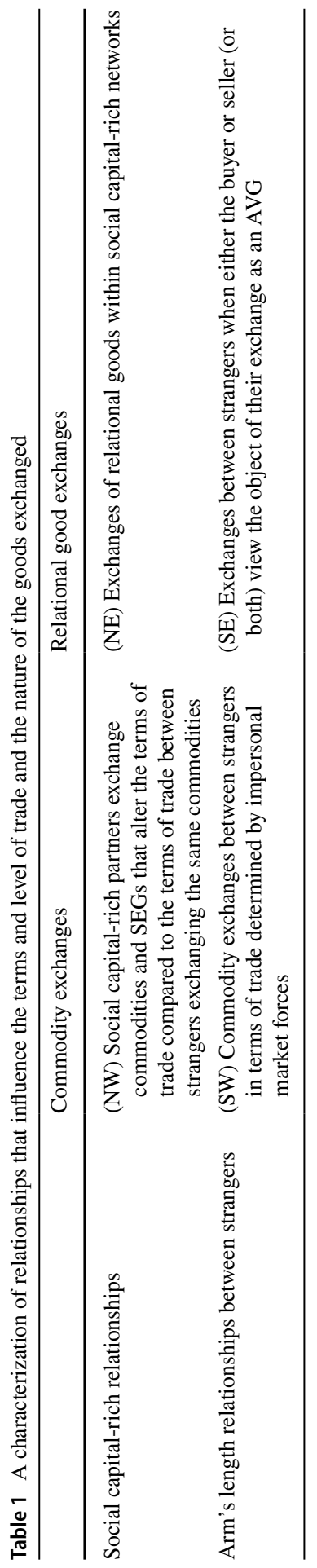




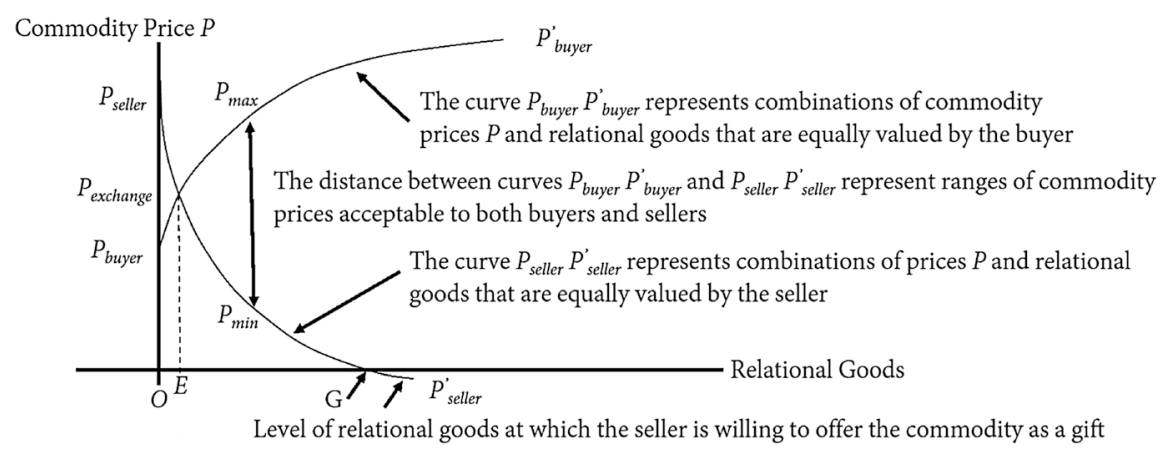

Fig. 1 Isoquants and economic exchange anomalies

both buyer and seller would appear to be nicer and more anxious to cooperate and trade than would be predicted by the neoclassical model.

Of course, we need to consider exchanges in which the relational goods exchanged between buyers and sellers are not symmetrical. For example, suppose the seller received relational goods OG, while the buyer received only commodities in the exchange. In this case, the buyer's maximum bid price measured on the vertical axis would equal $P_{\text {buyer }}$, while the seller's minimum sell price would be zero, a gift. Since $P_{\text {buyer }}>0$, a mutually agreeable price $P$ such that $0<P<P_{\text {buyer }}$ exists and the exchange occurs.

We provide two illustrations of how relationships influence the terms and level of exchange and the relationships between exchange partners. In the neoclassical model, the relationship between parties in any mutually agreeable transaction is not supposed to affect the terms of trade. However, Robison and Schmid (1991) observed that relationships alter the minimum sell price of used cars. Perry and Robison (2001) observed that the terms of trade for farmland also depended on relationships.

\section{The production of AVGs}

We now focus on processes that embed SEGs in tangible objects to create AVGs by associating a social capital-rich person(s) with an object. AVGs are important because they allow persons in a social capital-rich network to exchange relational goods even when members of the network are not in physical proximity.

Identifying AVG creating processes is an important part of the social capital synthesis because it is observable and can be used as the basis for a research agenda that tests and analyzes the importance of relational goods - a research agenda we support.

In what follows, we identify several AVG creating processes that produce objects whose value and meaning is changed by connecting it to a person. Treating an object as an AVG rather than a commodity is what some have described as irrational, paradoxical, or misbehaving. 
The endowment effect Thaler and colleagues made famous the endowment effect when they experimented with Cornell University coffee mugs. They demonstrated that after owning the coffee mugs, their owners valued them more. In this AVG creating process, coffee mug owners changed the value and meaning of the mugs by owning and associating themselves with the object. Of course, creating attachment value by owning an object is not limited to coffee mugs. We may create attachment value by owning cars, boats, furniture, clothes, and homes (Kahneman et al. 1990).

The IKEA effect We recognize IKEA stores for offering consumer durables with some assembly required. Then, as we change the form and value of the assembly-required objects, we associate ourselves with the object, creating attachment value in the process. As a result, we value the objects we assembled more than their commodity equivalent. The IKEA effect applies to multiple objects that require our efforts during which time we associate ourselves with the objects. The IKEA effect may apply to paintings, lawns and landscapes, music we practice or create, clothes we make or wear, schools we attend, and causes to which we contribute.

The honorific effect Honorific objects such as plaques, certificates, licenses, and other tangible validating evidence presented by persons in authority and esteemed by their recipients acquire attachment value. They have attachment value to the recipient because they providing evidence that he or she has achieved something noteworthy and meritorious by someone with social capital. As a result, the tangible evidence of validation is an AVG and valued quite differently than their commodity equivalent.

The sensory effect One AVG creating process connects a person to an object through sensory sensations of smell, sound, touch, taste, or sight. To increase the attachment value for an object, car salespeople recognize the importance of persons touching or driving a car. Positive sensory experiences increase the likelihood that persons experiencing the car will eventually purchase it. Shaking hands, hugging, and kissing another person often strengthen relationships between people as does spending time together. Visiting special place such as camping in a wilderness setting or caring for a pet all has the potential for creating AVGs through sensory experiences. As a result, we value the object of our sensory experience differently than we did before the sensation.

The commitment effect We sometimes strengthen social capital-rich relationships by participating in commitment ceremonies and exchanging physical symbols of commitment. As a result, people often expend significant sums to experience commitment ceremonies and to purchase commitment symbols. The average cost of a wedding in the USA in 2017, a commitment ceremony, was $\$ 25,764$ (The Wedding Report, Inc. 2019). Expenditures on symbols associated with the commitment such as rings, special clothing, reserved places where the commitment occurs are all part of the commitment process that creates AVGs out of otherwise ordinary events and 
objects. The expenditures themselves are evidence that the objects associated with the commitment are valued differently than their commodity equivalent.

The association effect Advertisers want to create attachment value for what would otherwise be commodities. To create attachment value for their commodities, advertisers are willing to pay famous persons with high esteem and regard from a large fan base to endorse their products. To illustrate, Michael Jordan earns around $\$ 60$ million each year for associating with Nike products (Arshad 2014).

Sometimes the famous persons associate not with a single object, but with a collection of objects with the same brand. Of course, the success of the association effect depends on the high-profile person maintaining the social capital of his or her fans and is sometimes lost when the high-profile person performs poorly and makes less than admirable choices. That high-profile persons earn significant sums to associate with endorsed products is evidence of their ability to create attachment values.

The membership effect Belonging in a network provides a SEG that satisfies a socioemotional need. Goods that signal that we belong to a network often acquire attachment value and become AVGs. Belonging symbols with attachment value include fraternity and sorority Greek letters, club symbols such as a Lion, a wagon wheel, and Elks; school colors and mascots, religious symbols such as the Star of David, the Crescent, and the Cross all signal belonging and likely to become AVGs.

The anthropomorphizing effect One interesting way to build a connection between an object and a person is to anthropomorphize it. Anthropomorphizing an object changes the relationship between a person and an object to a relationship between a person and an AVG-almost another person. The Tom Hanks character in the movie "Cast Away" provides an anthropomorphizing example. "Cast Away" is a 2000 film by Twentieth Century Fox about a FedEx employee who is stranded on a deserted island after his plane goes down over the South Pacific. Hank's character creates a humanlike companion out of a Wilson soccer ball-to provide relational goods on an otherwise deserted island. As a result, Hank's character no longer treats the soccer ball as a soccer ball.

Word framing effect Words can acquire attachment value when they become associated with social capital persons and AVGs. Advertisers often employ high attachment value words to improve the demand for and the price customers are willing to pay for their products. For example, words like fat, risk, old, used, sick, and die appear to have negative attachment value. Meanwhile, low fat, safe, pre-owned, recovering, and passing have improved attachment value while describing nearly identical products and events. Consider buying ice cream that is $10 \%$ fat versus the same product that is $90 \%$ fat free. Or, consider purchasing a used car versus a preowned car? 
The challenge with attachment value words is that experimental and randomized control trials gather data using words that may have attachment value. As a result, survey respondents often respond to the attachment value of words rather than their objective content (Tversky and Kahneman 1981). Allais demonstrated how comingling of high attachment value and object value words produced paradoxical behavior compared to outcomes predicted by the expected utility (Allais 1997). Robison, Shupp, and Myers explained the paradox by recognizing the difference attachment values to words like "certain" and "risk" used to gather preference data (Robison et al. 2010).

Reciprocity effect Retailers create AVGs so that consumers will feel a sense of obligation to make purchases. Cialdini (2016) described one such process called the reciprocity effect. The principle of reciprocity in sales psychology means that when we receive something free, we feel compelled to give something back to whomever provided the gift. One well-known example of the reciprocity effect occurs when we visit a store offering free samples, we often end up making purchases we did not intend to make. The synthesis explanation is that the product acquired attachment value because it was offered as a gift. Alternatively, the person offering the gift earned social capital and so we treat them differently than a stranger.

Other AVG creating processes One can image many more AVG creating processes than those listed here. Indeed, any process that creates an association between a person and an object is a possible AVG creating process as long as the person has social capital or if the object is associated with another AVG object. For example, imitations of AVG objects like famous painting, flags, replicas of objects associated with famous person can all become AVGs and are no longer merely commodities.

The importance of relational goods Why should we care about relational goods and the various ways we can create them? Or, to ask the question another way: so what? One answer is this. Commodities cannot satisfy our socio-emotional needs, and attempts to use them for satisfying socio-emotional needs we claim will be unproductive and inefficient. Furthermore, our resources available to create commodities are limited. Less limited are the resources that we can use to create relational goods that may be more important to our happiness than commodities.

Relational goods are also important because much of what occurs in our economy is creating and exchanging relational goods. To ignore the existence of relational goods is to be content with our inability to understand and predict predictably irrational behavior. To illustrate the importance of creating and exchanging relational goods, we note that consumers spend $\$ 2.6$ billion annually during the holiday season to create attachment values for things by packaging, wrapping, and decorating objects. In the process, Americans consumed 85 million tons of paper products. Indeed, wrapping paper and shopping bags on their own accounted for about 4 million tons of the trash. For what purpose? The most obvious answer is to create attachment values for commodities exchanges as gifts (Garber 2012). Surely, there must be a more efficient way to 
create attachment value for things— but we need to acknowledge their existence and importance.

\section{Rationalizing irrational exchanges using the social capital synthesis}

We claim that the social capital synthesis proposed in this paper can rationalize some behavior that would otherwise appear to be irrational when compared to neoclassical economic explanations and predictions. We now proceed to illustrate our claim for the synthesis' ability to provide rational explanations for what would otherwise appear to be misbehaving or making predictably irrational choices.

Including the cost of a relational bad Gneezy investigated the role of fines in "everyday life." He described a day-care center in Haifa Israel that intended to close at $4 \mathrm{pm}$ and depended on the good will of parents to pick up their children on time. Most of the time, parents picked up their children before $4 \mathrm{pm}$ and rarely picked up their children after 4:30 pm. Researchers studying parents' children pickup behavior suggested that one reason for the infrequent late pickups was the cost of facing the day-care teachers and apologizing for inconveniencing them-what we would call a relational bad.

In one experiment, some day-care centers, to reduce even more late pickups, instituted a fine for arriving late to pick up one's child. The outcome of the late pickup fine was unexpected. Late pickups increased (Gneezy 2013). Consider a social capital synthesis explanation for the unpredicted increase in late pickups.

Assume that parents' marginal utility per hour of day-care service is unchanged by instituting a fine for parents being late to pick up their children. Then, an increase in late pickups after imposing a fine must be attributable to changes in the marginal cost of childcare service.

Let $p_{\mathrm{c}}$ be the marginal commodity cost per hour $h$ of childcare services for $h<\bar{h}$ where $\bar{h}$ is the maximum contracted hours of service. Let $p_{\mathrm{b}}$ be the marginal relational bad cost per hour $h$ of childcare services for $h>\bar{h}$ so that the total marginal cost per hour for parents' picking up their children late was $\left(p_{\mathrm{c}}+p_{\mathrm{b}}\right)$.

If the late fine increased the marginal commodity cost by $\Delta p_{\mathrm{c}}$, then the marginal cost for parents picking up their children late would have increased and parents should have responded by reducing late pickups. But suppose that in addition to the increase in marginal commodity cost, relational bads decreased by $\Delta p_{\mathrm{b}}<0$ because parents no longer felt guilty for being late-they were paying commodities for the right. Then, if $\left(\Delta p_{\mathrm{c}}+\Delta p_{\mathrm{b}}\right)<0$, then the marginal cost of parents picking up their children late decreased and we should expect parents respond to the new incentives by increasing late pickups.

Accounting for attachment values An early observations motivating Thaler to study behavioral economics was the following. 
The chair of the department at the University of Rochester where Thaler studied economics (and one of his advisors), Richard Rosett, was a wine lover who had begun buying and collecting wine in the 1950s. For as little as $\$ 5$, he had purchased some choice bottles that he could now sell to a local retailer for $\$ 100$. Rosett had a rule against paying more than $\$ 30$ for a bottle of wine but he refused to sell his $\$ 100$ bottles of wine. Instead, he would drink them on special occasions. In summary, he would enjoy his old bottles worth $\$ 100$ each but he would neither buy nor sell wine at that price. Therefore, his marginal utility for a particular bottle of wine was both higher and lower than $\$ 100$ (Thaler 2018).

So how can the social capital synthesis explain this paradox? Easily-by recognizing that owning an object is one means by which an object acquires attachment value - the endowment effect. In this example, the attachment value and commodity value for a particular bottle of wine both increased over time. If Rosett had sold the wine, he would have received the wine's commodity value of $\$ 100$ but would have lost its attachment value that we must assume was greater than $\$ 70$. Rosett refused to sell a bottle of the wine he already owned. On the other hand, a bottle of wine that Rosett does not own lacks attachment value and its marginal commodity value of $\$ 100$ was greater than Rosett's marginal commodity value of new wine equal to $\$ 30$. So, he refused to purchase the $\$ 100$ bottle of wine.

Sunk costs and attachment values Sunk costs and opportunity costs are important economic concepts. The sunk cost for an object is money already spent-gone and not relevant to future choices that depend on opportunity cost or what one sacrifices in the future to make another purchase. However, behavioral economists have found that sunk costs do matter for future choices-presenting yet another example of humans not behaving like econs. Thaler provides an example of how sunk costs apparently do matter.

My friend Jeffrey and I were given two tickets to a professional basketball game in Buffalo, normally a 75-minute drive from Rochester. On the day of the game, there was a snowstorm and we sensibly decided to skip the game. But Jeffrey, who is not an economist, remarked, "If we had paid full price for those tickets we would have gone!" As an observation about human behavior, he was right, but according to economic theory, sunk costs do not matter. Why is going to the game more attractive if we have higher sunk cost? (Thaler 2018).

Thaler explains the basketball ticket conundrum as follows. Not going to the game requires that the ticket holders declare the sunk costs as a loss-but no loss is incurred if the tickets were a gift, but a significant loss if the tickets were purchased. We think there is another explanation.

The cost of not using the tickets includes the value of the lost entertainment $E$. The cost of using the tickets is traveling in the snowstorm $S$. However, Thaler and his friend Jeff created attachment value for the tickets when they purchased them equal 
to $\operatorname{AV}(T)$ that is only lost if the tickets are not used. In the case of the gifted tickets $(E<S)$, they miss the game. In the case of the purchased tickets $[E>S-\operatorname{AV}(T)]$, they would attend the game despite the snowstorm.

Similarly, reasoning can explain why investors tend to hold on to bad investments longer that rational investment behavior would predict even though the commodity loss is a sunk cost. Purchasing the investment creates attachment value for the investment that is not lost unless or until the investor unloads his or her bad investment (Taylor 2018).

Whose turn to pay? Two college professors frequently lunch together at a Chinese restaurant where they order the restaurant's buffet. As a result, the total cost for both of their meals is the same every time they lunch together. During the many years they have frequented the Chinese buffet, they alternate paying for lunch. Whether they alternate or not, the amount they each spend on their lunches is the same. So why do they alternate? A social capital synthesis explanation follows. Paying individually, each receives a commodity and pays for the commodity with cashanother commodity. When they alternate paying for each other's meal, they signal regard, trust, and even caring for each other-relational goods. As a result, without increasing the commodity cost of the meals, they increase the relational goods they produce by alternatively paying for each other's meal.

Commodification The social capital synthesis provides an important explanation for the important and well-recognized process of converting a relational good into a commodity, a process Oliver and Robison refer to as commodification (Oliver and Robison 2017).

In most cases, it is impossible to acquire relational goods in exchange for money because the relationship that created the relational good is not included in the exchange. As a result, while the purchaser intended to acquire the relational good, all that he or she receives in the exchange is a commodity (Cohen 2003; Cook 2004).

Consider how commodification can explain what appears to be irrational behavior. The American Association of Retired People (AARP) asked some lawyers to provide needy retirees legal services in exchange for $\$ 30$. The lawyers did not accept their offer. However, when the lawyers were asked to offer free legal services, they agreed (Sandel 2013). The synthesis explanation for this behavior is straightforward. In exchange for providing free legal services to the needy, lawyers receive relational goods that are sufficient to compensate them for their services. However, when AARA offered the lawyers $\$ 30$ for their services, they commodified the relational good the lawyers would have received by providing free legal services.

Mental accounting Mental accounting refers to the concept that individuals think of value in relative rather than absolute terms (Thaler 1985). For example, the theory might suggest that a consumer has two expense accounts for goods $x$ and $y$ limited to $X$ and $Y$, respectively. Mental accounting asserts that if expenses in account $X$ have 
reached their limit $(x=X)$, no further expenses for $X$ will be incurred even though expenditure for $y$ are under budget $(y<Y)$. As a result of mental accounting, if $C$ is a mental accounting cost function, $C[(x=X)+(y<Y)]>C[(x+y)<(X+Y)]$.

The social capital synthesis explanation for mental accounting is that in the process of fixing budget limits, we create SEG by spending less that the account limit and socio-emotional bads for spending more than the account maximum. As a result, we treat expenditures on $x$ as though they are independent of expenditures on $y$ even though they come from the same account. This leads to predictably irrational behavior in which we exert the same effort trying to buy inexpensive gasoline to save a few dollars than we do spend buying a car and saving hundreds of dollars.

\section{The social capital synthesis and rural development}

Traditional views of rural development and social capital We characterize rural development as the process of improving the well-being of people living in isolated and sparsely populated areas (Moseley 2003). There is a rich literature describing the challenges of rural development from a traditional perspective. Perhaps the most important rural development challenge is the low densities of economic agents that limit learning from each other and exchanges that permit increased specialization and productivity. Duranton and Puga (2004) discussed these challenges and others. Related to the low density of economic agents in rural area and limited exchange opportunities are limited opportunities to build social capital and avoid building negative social capital.

Another significant challenge restricting rural development is the formation of trading relationships outside of the rural area networks. Westlund (2019) argues that rural areas that are located outside the positive influence of city regions lack potential for increases in exogenous demand for their products or resources that can stimulate their economies to grow. This perspective suggests that development in rural areas is disadvantaged because of a lack of external social capital including social capital with external actors and market participants. This challenge suggests that rural development can benefit by investing in social capital with external actors and market participants in areas outside of their rural networks.

Measures of rural development One way to measure rural development is by changes in the average and variance of household incomes in rural areas. Elsewhere, colleagues and I defend average and variance of household income measures of both commodity and social well-being for the following reasons. First, among a perfectly rich social capital-rich network whose members value each other's well-being equal to their own, household incomes would be equal because the marginal utilities of relational goods and commodities would be equal within and across households. 
Furthermore, in a perfectly rich social capital network (think of a well-functioning family) where member internalize each other's well-being, network members act as a single profit-maximizing firm since the commodity benefits will be equally distributed. Therefore, the perfect social capital-rich network maximizes the average level of household income. As social capital within a network decreases, Robison, Siles, and Jin find that the average level of household income decreases and the variance of household incomes increases (Robison et al. 2011).

Cheap social capital and constraints on rural development Network members build cheap social capital among themselves by finding persons not like them who they can agree to blame, marginalize, punish, or disadvantage. If social capital is sympathy or empathy, cheap social capital depends on creating antipathy and insensitivity for those outside of one's network. Indeed, despotic power depends on having supporters who agree to "hate" or "fear" the persons or groups vilified by the despot. Members of minority or marginalize ethnic or religious groups, those who fail to adhere to generally accepted norms, those who disagree with persons in power, or those who lack political or economic power are popular objects of cheap social capital.

Cheap social capital disadvantages both those who share it and those who are its object. Objects of cheap social capital often experience policies and actions affecting their access to resources and opportunities that would contribute to their commodity well-being. However, members of cheap social capital network often also suffer. First, cheap social capital connected networks often expend commodities in an effort to disadvantage the objects of their antipathy. Second, they are disadvantaged because relational bads prevent their exchanging goods and services with the objects of their antipathy and thus deny themselves the advantages that such exchanges could produce.

Cheap social capital is particularly destructive in rural development settings because the size of the networks is small and divisions among small groups are particularly anti-productive. A simple model will make this point-that divisions attributed to cheap social capital are anti-productive. Believe Adam Smith (1776) that specialization increases productivity. In the case of pin production, one person working alone could produce 1 pin a day, while 10 persons working together and specializing in pin producing tasks could make 48,000 pins a day. Now apply the concept to a rural population.

Suppose that within an $n$-person population there are $n(n-1)$ ways the population could form a 2-person enterprise. Now suppose the population suffered one division so that they would no longer trade with each other. Now there are only $n(n / 2-1)$ ways the population could form a 2-person enterprise-approximately $50 \%$ as many as could have been formed without the division. And with two divisions, the possible combinations of 2-person business drop to $33 \%$ of its original number. We describe, in Table 2, other consequences of division on opportunities to specialize in one-ten-person enterprises. 
Table 2 Percentage of goods produced after division(s) compared to the original number of goods produced before division(s)

\begin{tabular}{lrrrrrrrrr}
\hline $\begin{array}{l}\text { Number of groups } \\
\text { after division(s) }\end{array}$ & \multicolumn{8}{l}{ Number of unique inputs required per good produced (\%) } \\
\cline { 2 - 10 } & \multicolumn{1}{c}{$(2)$} & \multicolumn{1}{c}{$(3)$} & \multicolumn{1}{c}{$(4)$} & \multicolumn{1}{c}{$(5)$} & \multicolumn{1}{c}{$(6)$} & \multicolumn{1}{c}{$(7)$} & $(8)$ & $(9)$ & $(10)$ \\
\hline 1 & 100 & 100 & 100 & 100 & 100 & 100 & 100 & 100 & 100 \\
2 & 50 & 25 & 13 & 6 & 3 & 2 & 0 & 0 & 0 \\
3 & 33 & 11 & 4 & 1 & 0 & 0 & 0 & 0 & 0 \\
4 & 25 & 6 & 2 & 0 & 0 & 0 & 0 & 0 & 0 \\
5 & 20 & 4 & 1 & 0 & 0 & 0 & 0 & 0 & 0 \\
6 & 17 & 3 & 0 & 0 & 0 & 0 & 0 & 0 & 0 \\
7 & 14 & 2 & 0 & 0 & 0 & 0 & 0 & 0 & 0 \\
8 & 13 & 2 & 0 & 0 & 0 & 0 & 0 & 0 & 0 \\
\hline
\end{tabular}

The point here is that cheap social capital that divides the rural population into fragmented social capital networks that refuse to trade with each other limits opportunities to specialize and productivity.

Internalizing externalities Particularly relevant to rural development is how rural residents and communities manage their externalities and shared resources. Social capital internalizes the well-being of persons in a social capital-rich network. Furthermore, in a rich social capital network, network members treat shared resources as though they belonged to a single firm intent on maximizing the benefits from the resource. Nobel Prize winner Eleanor Ostrom (1990) described how a social capitalrich network of Swiss dairy farmers managed their common resource as though it were privately owned and managed to maximize profits.

Social capital and cooperatives Sometimes social capital-rich networks form into cooperatives that act as a single firm maximizing their collective well-being. In other cases, their internalization of each other's well-being reduces the risk each individual member would face without the cooperative. Finally, their collective social capital provides incentives to fund the purchase of public goods whose benefits accrue to the collective rather to any one individual. Examples of such projects may include storage facilities, lighting services, security services, communication equipment, increased marketing power, to name a few.

AVG and constraints on innovation Repeated operations and contact with an object such as a farming implement are likely to create attachment value, particularly when these operations and objects are associated with other high social capital persons in one's network. In most cases, we view the creation of AVGs as positive and as a way of storing one's relational goods. However, the creation of AVGs may have negative consequences when we create attachment values for inefficient or even harmful methods of producing commodities. 
Recognizing that in some cases attachment values may limit the adoption of new and more efficient methods of production suggests that efforts to increase adoption of more efficient production methods will require more than demonstrating the commodity advantages of the new methods. It will require creating attachment values for new methods, machines, and ways of governance (Easterly 2001).

\section{Conclusions}

This paper introduced a social capital synthesis that includes important features of neoclassical economics, behavioral economics, and socioeconomics. The goal was to produce a model that would explain some observed behavior that appears to be irrational when compared to the predictions and explanations of neoclassical economic models. We pointed out that the assumptions of the neoclassical, socioeconomic and behavioral economic models are all relevant in some conditions and some of the time depending on the relationships of persons connected to the production and exchange of goods and the kinds of goods exchanged.

To understand the contributions of behavioral and socioeconomics, we contrasted commodities with relational goods and noted that neoclassical economics is adept at explaining the exchange of commodities between strangers while the social capital synthesis is appropriate for explaining exchanges of relational goods in social capital-rich networks.

To increase awareness of relational goods, this paper described several processes for creating attachment value goods-a relational good. Just as we cannot ignore production processes that produce commodities, we cannot ignore the processes that produce relational goods and successfully understand social exchanges. Understanding both commodity and relational good production processes will help us manage all of our capital, including social capital, more efficiently.

Finally, we noted that social capital plays an important role in rural development for either good or bad. Building cheap social capital within a group by disparaging, demeaning, or placing others at a disadvantage limits gains that we could win by specialization and trade. On the other hand, social capital-rich networks can produce cooperative efforts that win rewards beyond those produced by commodity markets by internalizing externalities that limit the production of negative externalities and increase investments in goods whose benefits are shared independently of amounts donated. Finally, to be generally accepted within the social sciences, the social capital synthesis needs more testing and study—an effort we enthusiastically support.

Open Access This article is distributed under the terms of the Creative Commons Attribution 4.0 International License (http://creativecommons.org/licenses/by/4.0/), which permits unrestricted use, distribution, and reproduction in any medium, provided you give appropriate credit to the original author(s) and the source, provide a link to the Creative Commons license, and indicate if changes were made. 


\section{References}

Allais M (1997) An outline of my main contributions to economic science. Am Econ Rev Am Econ Assoc 87(6):3-12

Ariely D (2008) Predictable irrational: the hidden forces that shape our decisions. Harper, New York

Arshad S (2014) Nike's top 10 highest paid endorsement deals to sports players. Retrieved from TSM Plug: http://www.tsmplug.com/richlist/nike-highest-paid-endorsement-deals/

Becchetti L (2008) Relational goods, sociability, and happiness. Center Econ Int Stud 6(4):1-27

Blau P (1964) Exchange and power in social life. Transaction Publishers, Piscataway, NJ

Bruni L, Stanca L (2008) Watching alone: relational goods, television and happiness. J Econ Behav Organ 65:506-528

Burt R (1992) Structural holes: the social structure of competition. Harvard University Press, p 9

Cialdini R (2016) Pre-suasion: a revolutionary way to influence and persuade. Simon \& Schuster, New York, NY, USA

Cohen I (2003) The price of everything, the value of nothing: reframing the commodification debate. Harv Law Rev 117(689):689-710

Coleman J (1990) Foundations of social theory. Harvard University Press, Cambridge

Cook DT (2004) The commodification of childhood: the children's clothing industry and the RIse of the child consumer. Duke University Press, Durham

Duranton G, Puga D (2004) Micro-foundations of urban agglomeration economies. Henderson J, Thisse $\mathbf{J}$ (eds) Handbook of regional and Urban economics, edn 1, vol 4, chapter 48. Elsevier, pp 2063-2117

Easterly W (2001) The middle class consensus and economic development. J Econ Growth 6(4):317-335

Emerson R (1976) Social exchange theory. Ann Rev Sociol 2:335-362

Etzioni A (2010) The moral dimension: toward a new economics. Simon and Schuster, New York, NY

Fukuyama F (2001) Social capital, civil society and development. Third World Quarterly 22:1, 7-20

Garber J (2012) Wrappers' delight: a brief history of wrapping paper. Disguising presents with decorative sheets of paper is, like so many other things, an accident of history. https://www.theatlanti c.com/technology/archive/2012/12/wrappers-delight-a-brief-history-of-wrapping-paper/266599/

Gneezy U (2013) The why axis: hidden motives and the undiscovered economics of everyday life. Public Affairs, New York

Gui B, Stanca L (2010) Happiness and relational goods: well-being and interpersonal relations in the economic sphere. Int Rev Econ 57(2):105-118

Gui B, Sugden R (2005) Economic and social interaction: accounting for interpersonal relations. Cambridge University Press, Cambridge

Homans G (1958) Social behavior as exchange. Am J Sociol 63(6):597-606

Kahneman D, Knetsch J, Thaler R (1990) Experimental tests of the endowment effect and the Coase theorem. J Polit Econ 98(6): 1325-1348

Luigino B, Stanca L (2008) Watching alone: relational goods, television and happiness. J Econ Behav Organ 65(3,4):506-528

Maslow A (1943) A theory of human motivation. Psychol Rev 50(4):370-396

Mastroeni T (2017) What is an arm's length transaction? Fair and square real estate sales. https://www. realtor.com/advice/buy/what-is-an-arms-length-transaction/

Moseley M (2003) Rural development, principles and practice. Sage, Thousands Oaks, CA

Oliver J, Robison L (2017) Rationalizing inconsistent definitions of commodification: a social exchange perspective. Mod Econ 8(11):1314-1327

Ostrom E (1990) Governing the commons. Cambridge University Press, Cambridge

Perry G, Robison L (2001) Evaluating the influence of personal relationships on land sale prices: a case study in Oregon. Land Econ 77(3):385-398

Portes A, Sensenbrenner J (1993) Embeddedness and immigration: notes on the social determinants of economic action. Am J Soc 98:1320-1350

Putnam R (2001) Bowling alone: the collapse and revival of American community. Simon and Schuster, New York

Robison L, Flora J (2003) The social capital paradigm: bridging across disciplines. Am J Agr Econ 85(5):1187-1193

Robison L, Ritchie B (2010) Relationship economics: the social capital paradigm and its application to business, politics, and other transactions. Grower Publishers, New York 
Robison L, Schmid A (1991) Interpersonal relationships and preferences: evidence and implications. In: Handbook of behavioral economics, vol 2. pp 347-358

Robison L, Schmid A, Siles M (2002) Is social capital really capital? Rev Soc Econ 60(1):1-21

Robison L, Shupp R, Myers R (2010) Expected utility paradoxes. J Socio-Economics 39(2):187-193

Robison L, Siles M, Jin S (2011) Social capital and the distribution of household income in the United States. J Socioecon 40(5):538-547

Sandel M (2013) What money can't buy: the limits of markets. Straus \& Giroux, New York

Smith A (1759) The theory of moral sentiments. Clarendon Press, Oxford

Smith A (1776) The wealth of nations. W. Strahan and T. Cadell, London

Taylor T (2018) Thaler on the evolution of behavioral economics. Retrieved from BBN Times: https:// www.bbntimes.com/en/global-economy/thaler-on-the-evolution-of-behavioral-economics

Thaler R (1985) Mental accounting and consumer choice. Mark Sci 4:199-214

Thaler R (1992) The Winner's Curse: Paradoxes and Anomalies of Economic Life. Princeton University Press, Princeton, p 5

Thaler R (2016) Misbehaving: the making of behavioral economics. W.W. Norton \& Company, New York

Thaler R (2018) Behavioral economics from nuts to 'nudges': a bowl of cashews led to a research breakthrough. Retrieved from Chicago Booth Review: http://review.chicagobooth.edu/behavioral-scien ce/2018/article/behavioral-economics-nuts-nudges

Thaler R, Sunstein C (2008) Nudge: improving decisions about health, wealth, and happiness. Yale University Press, New Haven

The Wedding Report, Inc. (2019) costofwedding.com. Retrieved from https://www.costofwedding.com/

Tversky A, Kahneman D (1981) The framing of decisions and the psychology of choice. Sci New Series 211(4481):453-458

Uhlaner C (1989) Relational goods and participation: incorporating sociability into a theory of rational action. Public Choice 62(3):253-285

Westlund H (2019) Urban - rural relations in the post-urban world. Emergent transformation of cities and regions in the innovative global economy, Publisher: Routledge, pp 70-81

Publisher's Note Springer Nature remains neutral with regard to jurisdictional claims in published maps and institutional affiliations. 